\title{
Biopolitics via political psychology Comment in response to Liesen and Walsh
}

\author{
Rebecca J. Hannagan \\ Department of Political Science \\ Northern Illinois University \\ Zulauf Hall 401 \\ Dekalb, IL 60115 \\ rhannaga@niu.edu
}

I

$\mathrm{n}$ 'The competing meanings of 'biopolitics' in political science: Biological and postmodern approaches to politics," Laurette Liesen and Mary Walsh argue that two very distinct groups of political scientists have organized their work around the term "biopolitics." The authors suggest that these areas of research are not only qualitatively different, but also potentially contradictory. I agree that the distinction between the camps is a meaningful one. But since the current more "scientific" scholars focusing on biological approaches to politics are not identifying with the term "biopolitics," it may neither be possible nor necessary to rebrand by attempting to reclaim the term "biopolitics" from the postmodern camp or utilize a label such as "neuropolitics." Rather, those pursuing this work tend to already identify with the subfield of political psychology-a field that has been expanding to encompass an even more multidisciplinary approach to the study of political attitudes and behavior.

\section{Recent 'scientific biopolitics' scholarship}

The discipline of political science appeals to many scholars because it is a big tent that accommodates many subfields, theoretical frameworks, and methodological approaches. Traditionally, there have been five subfields: Comparative Politics, International Relations, American Government and Politics, Political Theory, and Methodology. Though many departments still adhere to this five-category approach to organizing research, hiring faculty, and training graduate students,

doi: 10.2990/32_1_90 there are just as many departments that have opted to move away from this traditional categorization. Some departments have undertaken to organize themselves thematically or by methodological approach. "Democratization," for example, would embody a thematic approach that could unite those who study American government and politics as well as international relations or comparative politics perspectives and would otherwise be separated by the traditional subfield boundaries.

As Liesen and Walsh argue, the more "scientific biopolitics" camp of political scientists organized their work around theory, behavior, and policy. Although the unifying theme throughout their work was taking biology into account in models of human behavior, or using evolution as a way to enhance political theory, it was difficult to have a unified subfield tying behavior, policy and theory together. This may have been particularly true if scholars operated in departments organized by the traditional five-category approach.

In more thematically organized contexts, consistent with the current state of the discipline, it may have been less onerous for those pioneering scholars to unify. Using the term "biopolitics" may have been particularly strategic for those taking, what was in the 1970s and 1980s, a controversial approach. It could also be argued that the strategic use of the term "biopolitics" was necessary to bring coherence to their body of work because there actually was not much coherence among work encompassing the areas of public policy, political behavior, and political theory. Whether it was internal coherence among the body of work or the structure of the larger discipline they were operating in, the subject matter was problematic for 


\section{Biopolitics forum}

the early scientific biopolitical scholars in the sense that the work did not become mainstream as biopolitics (for more on this point see the Founders' Forum in the spring 2011 issue of this journal).

More recent scholarship undertaking a more scientific (as contrasted with postmodern) biological approach to the study of politics tends to signal that approach through the use of key words and phrases. In their article, Liesen and Walsh mention several of these terms, including: biopolitics, politics and the life sciences, neuropolitics, cognition and decision sciences, political psychology, evolutionary politics, genopolitics, and Darwinian politics. Recent paper titles illustrating this trend include:

- Political Attitudes Vary with Physiological Traits ${ }^{1}$

- An Evolutionary Account of Suicide Attacks: The Kamikaze Case ${ }^{2}$

- Is There a "Party" in Your Genes?

- Biology, Politics, and the Emerging Science of Human Nature ${ }^{4}$

- Women, Behavior, and Evolution ${ }^{5}$

- Is Political Cognition Like Riding a Bicycle? How Cognitive Neuroscience Can Inform Research on Political Thinking ${ }^{6}$

- Sex and the Shaheed: Insights from the Life Sciences on Islamic Suicide Terrorism ${ }^{7}$

I have highlighted these key words to show the variety of terms that are currently used by scholars. Although my search for articles was merely cursory, you can see that none of these titles utilize the term "biopolitics." This hints that strategic use of a word to unite this research is not being employed and is perhaps not necessary. Research in this area is more likely to be published in journals than in the form of books, but two books have been published recently that come to mind as examples of this approach: Political Psychology: Neuroscience, Genetics, and Politics, by George Marcus ${ }^{8}$ and Man Is by Nature a Political Animal: Evolution, Biology and Politics, edited by Peter K. Hatemi and Rose McDermott. ${ }^{9}$ Though these two books differ in their aims, both make significant headway toward biologically based theory building in the study of political attitudes and behavior.

What unites the few works I mention here for illustrative purposes (and countless other articles and books I have not mentioned for the sake of brevity) is not an identifying label, but the fact they are all undertaking a particular approach to studying political attitudes and behavior. The particular approach, as it turns out, places much of this work within the subfield of political psychology.

Political psychology has been expanding to encompass biological approaches for some time, just as the field of psychology did. The logical progression of the subfield is to incorporate the theoretical and methodological advances made in biology, neurobiology and psychology to the study of political attitudes and behaviors. Why is it a logical progression? Because we seek to explain phenomena by looking to processes one level down from what we are interested in. It makes sense to move in the direction of the biologically minded approaches because what we seek to understand is political behavior. The scholars undertaking the more scientific brand of "biopolitics" do not necessarily stem from a progression of scholars beginning with those identified by Liesen and Walsh, but are merely those whose training in political behavior and psychology is informed by the advances that have informed the field of psychology. This may explain why many of these scholars do not use the term "biopolitics" as a unifying term for their research agenda, as well as why they would not see the need for such a label-as they are already unified by the subfield of political psychology.

\section{'Biology minded' graduate programs}

Other evidence that the more recent embodiment of "biopolitics" research stems from the evolving subfield of political psychology comes from an examination of recent changes in graduate programs. Graduate programs in political science that focus on what Liesen and Walsh consider the more scientific biological approach to the study politics go by various names, as does the scholarship (as noted above). In my terse search for graduate programs that specialize in a more scientific biological approach, I did not identify any programs that explicitly use the term "biopolitics." The Political Science Department at Northern Illinois University historically had a Biopolitics concentration as part of its graduate program, but as of 2012 no longer offers the concentration. Again, the following examples are by no means meant to represent a comprehensive list of 


\section{Hannagan}

programs, but merely to highlight a few instances of current curricular approaches.

The first example is Vanderbilt University's Department of Political Science, which hosts the "Research on Individuals, Politics, and Society (RIPS)" initiative. The program's website states that:

This state-of-the-art lab hosts research studies on political attitudes and behavior while enriching the educational experience of graduate and undergraduate students. RIPS offers grants for graduate student research as well as student-faculty collaborations. The initiative is tied largely to faculty researchers and their graduate students in American political behavior and political psychology who utilize experimental methods.

Vanderbilt is an example of a program taking a step toward the more "scientific" biopolitics approach to the study of political attitudes and behavior, but is doing so entirely within the behavioralist tradition and under the umbrella of the subfield of political psychology. One of the progressive features of the RIPS initiative is that it goes beyond satisfying the research of specific faculty members and their graduate mentees to also enhance the experience of undergraduates.

The second example is the Department of Political Science at the University of California, Merced. UC Merced boasts an interdisciplinary focus at both the graduate and undergraduate levels. According to the department's website, at the graduate level students "can train with Cognitive Scientists, Psychologists, Economists, and Sociologists-in addition to Political Scientists-during their program of studies." The interdisciplinary nature of the program is argued to be "ideal for students particularly interested in political psychology or political economy." The subfields identified at Merced are Political Cognition and Behavior ( $\mathrm{CAB})$, and Political Institutions and Political Economy (PIPE), as opposed to the traditional five category subfields. The methods sequence they highlight includes "computational modeling and experimental methods, in addition to methods typical of the field of political science." Additionally, and like Vanderbilt, the department's undergraduate program offers emphases in political behavior as well as interdisciplinary approaches.
This program is another example of a way in which a department may organize such that contemporary approaches to the study of political behavior need not be inhibited by traditional categories like International Relations or American Government and Politics. Pedagogically, it may also enhance the experience of graduate and undergraduate students by allowing them to have a "behavioral" or "economic" approach to their studies.

The third example is the Department of Political Science at the University of Nebraska. Nebraska offers a program in Biology and Politics (SB2)-the SB2 stands for the Systems Biology of Social Behavior Initiative, which is an interdisciplinary group of researchers from Psychology, Political Science, Biological Sciences, Sociology, Economics, and Special Education and Communication Disorders. The Department of Political Science houses the Political Physiology Lab-a key part of the initiative. Political science faculty are also associates of the new Center for Brain, Biology, and Behavior (B3), which partners with the University of Nebraska athletics department to study the traumatic brain injury.

The Nebraska political science website states that, "the program promotes the idea that interdisciplinary training prepares students for thinking beyond disciplinary boundaries to solve problems as well as learning to work as part of a larger collaboration." Although some subfields in political science have been collaborative for some time (i.e., political psychology), this is still a fairly novel concept for some. Institutionalizing interdisciplinary collaboration represents the new terrain in political science and Vanderbilt, UC Merced, and Nebraska all represent different approaches to doing so while sharing the study of attitudes and behavior at their core.

\section{Biopolitics via political psychology}

The work that began with some pioneering political scientists in the 1960 s has come to fruition in the larger discipline as evidenced by conference panels and keynotes at the American Political Science Association annual meeting, a wave of innovative scholarship and methods workshops, the hiring of faculty with an interdisciplinary and collaborative outlook, and new, cross-cutting approaches to graduate programs. To say 


\section{Biopolitics forum}

that the term biopolitics is no longer being used, nor particularly necessary for current biology-minded political scientists, is not to say that the groundwork began in the 1960s was not incredibly necessary and valuable. Graduate students who are training and assistant professors who are publishing are currently operating in a very different environment-one characterized by less rigid adherence to the traditional subfield approach, and that encourages interdisciplinary collaboration and cutting-edge methodologies.

A unifying term is no longer needed and the postmodernists can keep it-as long as they do not borrow "political psychology" as well.

\section{References}

1. R. Douglas Oxley, Kevin B. Smith, John R. Alford, Matthew V. Hibbing, Jennifer L. Miller, Mario Scalora, Peter K. Hatemi, and John R. Hibbing, "Political attitudes vary with physiological traits, " Science, 2008, 321(5896): 16671670 .

2. John Orbell, and Tomonori Morikawa, "An evolutionary account of suicide attacks: The kamikaze case," Political Psychology, 2011, 32(2): 297-322.
3. Peter K. Hatemi, John R. Alford, John R. Hibbing, Nicholas G. Martin, and Lindon J. Eaves, "Is there a 'party' in your genes?" Political Research Quarterly, 2009, 62(3): 584-600.

4. James H. Fowler and Darren Schreiber, "Biology, politics, and the emerging science of human nature, "Science, 2008, 322 (5903): 912-914.

5. Laurette T. Liesen, "Women, behavior and evolution," Politics and the Life Sciences, 2007, 26(1): 51-70.

6. Matthew D. Lieberman, Darren Schreiber, and Kevin N. Oschner, "Is political cognition like riding a bicycle? How cognitive neuroscience can inform research on political thinking," Political Psychology, 2003, 24(4): 681-704.

7. Bradley A. Thayer, and Valerie M. Hudson, "Sex and the shaheed: Insights from the life sciences on Islamic suicide terrorism, " International Security, 2010, 34(4): 37-62.

8. George Marcus, Political Psychology: Neuroscience, Genetics, and Politics (New York: Oxford University Press, 2012).

9. Peter K. Hatemi, and Rose McDermott, Man Is by Nature a Political Animal: Evolution, Biology, and Politics (Chicago: University of Chicago Press, 2011). 